\title{
Current optimal control method for three-phase dual active bridge converter in light load conditions
}

\author{
Xiaobin Mu, Xiang Wang, and Fengjiao Dai* \\ State Key Laboratory of Advanced Power Transmission Technology (Global Energy Interconnection \\ Research Institute Co., Ltd.), Changping District, Beijing 102209, China
}

\begin{abstract}
Three-phase dual active bridge converter has many performance advantages, and is widely used in electric vehicle charging, battery energy storage system, power electronic transformer, and other energy conversion occasions. However, in the traditional control method, it has the problem of low efficiency under light load conditions. In this paper, firstly, the power and current expressions of the converter under light load conditions are solved by time-domain analysis, and an optimal current control method under light load conditions is proposed. This control method can simultaneously realize the minimum inductance current stress and RMS. Finally, the effectiveness of this method is verified by experiments.
\end{abstract}

\section{Introduction}

In recent years, with the development and popularization of new renewable power generation, energy storage system has also been developed rapidly. The bidirectional DCDC converter, which can connect new energy power generation systems and energy storage systems is essential. There are more and more researches on DC-DC occasions such as DC microgrid. Literature [1] studies the dynamic impact of grid-connected inverters, proposes a method based on linearization and extra element theorem to model the effect of the feedforward control in the inverter dynamics. Literature [2] proposes a method for fault detection based on superimposed components of the fault present, which can effectively improve the reliability of the DC microgrid.

Three-phase dual active bridge converter (3p-DAB) has the advantages of large power capacity, bidirectional energy flow, and soft switching, which is suitable for high-power bidirectional energy applications. However, it also has the problems of low efficiency caused by backflow power under light load conditions.

In order to solve its problems under light load conditions, the literature [3] proposes the two-phase parallel operation method. It converts the three-phase structure into a singlephase full-bridge to use the $1 \mathrm{p}-\mathrm{DAB}$ control method. This method can improve the overall efficiency under light load, but it loses the small ripple of the three-phase structure.

\footnotetext{
*Corresponding author: daifengjiaosw@163.com
} 
Literature [4] proposes that the change of switches duty cycle can achieve higher performance, but only when the duty cycle is $1 / 3$ is analysed. Literature $[5,6]$ proposes simultaneous PWM control with the same duty cycle. Literature [7] proposed a duty cycle control method based on multiple harmonic approximation analysis, which can solve the three-degree-of-freedom global current RMS optimal solution, but it must be solved by offline calculation. It can only be realized by the look-up table method in the digital controller of the converter, which is not convenient. Literature [6] proposes a current stress optimal method in the full power range, but the effect of the current RMS is not considered.

In summary, the existing literature is not sufficient for the research of $3 p-D A B$ under light load conditions. This paper adopts the optimization method and proposes the optimal control method of the converter to improve the performance under light load conditions.

\section{3p-DAB analysis}

\section{$2.13 p-D A B$ working principle}

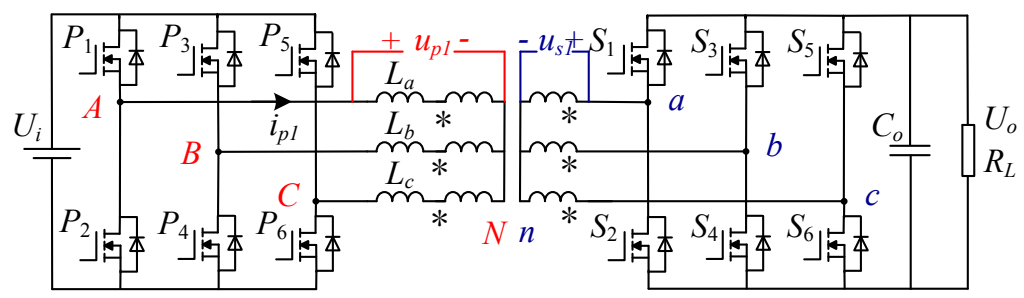

Fig. 1. 3p-DAB converter topology.

The 3p-DAB main circuit topology is shown as Fig.1, which is mainly composed of the primary side bridge arms, the three-phase high-frequency transformer, and the secondary side bridge arms. $P_{1}-P_{6}$ are the primary side switches, and $S_{1}-S_{6}$ are the secondary side switches, $L_{\mathrm{a}}, L_{\mathrm{b}}$, and $L_{\mathrm{c}}$ are the sum of the primary side leakage inductance of the threephase transformer and the secondary side converted to the primary side. The load resistance $R_{L}$ in this article can be defined by the quotient of the output voltage and current.

In SPS (single-phase-shift) control, the upper and lower switches of each bridge arm maintain a $50 \%$ duty cycle complementary conduction, and the three-phase bridge arms are alternately operated with $120^{\circ}$.

In addition to the phase shift angle, two other variables are introduced in the control method adopted in this article, the primary side bridge duty cycle and the secondary side bridge duty cycle. The control of these three variables can achieve higher performance.

\subsection{Power and current analysis}

This paper takes the forward boost conditions as an example for analysis. It is unfavorable for the inductor current and the realization of soft switching that the primary and secondary voltages are mismatched. Therefore, the duty cycle of the equivalent high-voltage side is generally smaller than that of the equivalent low-voltage side to achieve the matching of the primary and secondary voltages as much as possible. In the following analysis, it assumes that the duty cycle of the equivalent high-voltage side is smaller than the low-voltage side, and the duty cycle is relatively small in the light load, so there are the following conditions:

$$
0 \leq D_{2} \leq D_{1} \leq \frac{1}{3}
$$


In this light load conditions, it can be divided into three modes:

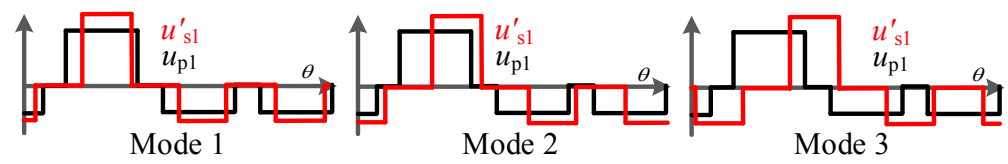

Fig. 2. The phase voltage of the three modes in light load conditions.

The following analysis takes Mode 2 as an example, and the analysis process of the other two are similar.

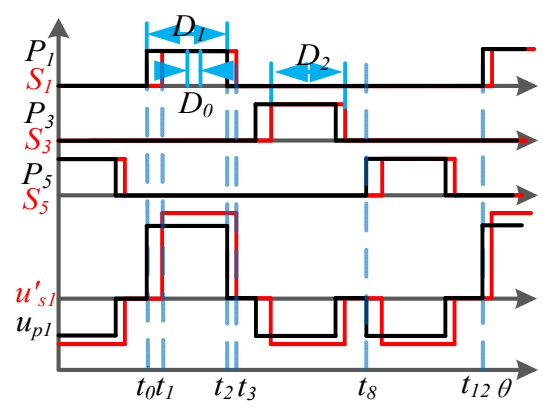

Fig. 3. Theoretical waveforms of Mode 2.

According to the phase voltage waveforms, the current expression at each moment can be obtained:

$$
\begin{array}{ll}
i(\theta)=i\left(t_{0}\right)+\frac{U_{i}}{3 \omega L}\left(\theta-t_{0}\right) & t_{0}<\theta \leq t_{1} \\
i(\theta)=i\left(t_{1}\right)+\frac{U_{i}-U_{o}^{\prime}}{3 \omega L}\left(\theta-t_{1}\right) & t_{1}<\theta \leq t_{2} \\
\cdots \cdots & \\
i(\theta)=i\left(t_{11}\right)+\frac{0}{3 \omega L}\left(\theta-t_{11}\right) & t_{11}<\theta \leq t_{12}
\end{array}
$$

Solve the initial value of current according to the volt-second balance method:

$$
I=\int_{t_{0}}^{t_{12}} i(\theta) \mathrm{d} \theta=0
$$

In order to simplify the subsequent analysis, first define the output and input voltage transformation ratio as $k$ :

$$
\frac{U_{o}}{U_{i}}=k
$$

The power and current stress expressions can be obtained and standardized:

$$
\begin{gathered}
P_{i}=\frac{3 U_{i}}{2 \pi} \int_{t_{0}}^{t_{2}} i(\theta) \mathrm{d} \theta \quad P_{p u}=\frac{2 \pi U_{i}^{2}}{L \omega} \quad I_{p u}=\frac{2 \pi U_{i}}{3 L \omega} \\
P_{i p u}=-(1 / 4)\left(D_{0}{ }^{2}+\left(D_{1}-D_{2}\right)^{2}-2 D_{0}\left(D_{1}+D_{2}\right)\right) k
\end{gathered}
$$




$$
I_{\max p u}=\frac{i\left(t_{1}\right)}{I_{p u}}=D_{0}+D_{2}(-1+k)
$$

Solve the current RMS expression in this working mode:

$$
I_{\mathrm{RMS}}=\int_{0}^{2 \pi} i(\theta)^{2} d \theta
$$

Finally, the expressions of power, current stress, and current RMS under different modes are obtained, as shown in Table.1 and Table.2. the current stress expressions of the three working conditions are the same: $D_{0}+D_{2}(-1+\mathrm{k})$.

Table 1. The power expressions of three modes.

\begin{tabular}{|c|c|}
\hline Mode & Power \\
\hline Mode 1 & $D_{0} D_{2} k$ \\
\hline Mode 2 & $-(1 / 4)\left(D_{0}^{2}+\left(D_{1}-D_{2}\right)^{2}-2 D_{0}\left(D_{1}+D_{2}\right)\right) k$ \\
\hline \multirow{2}{*}{ Mode 3 } & $-(1 / 72)\left(4+27 D_{0}^{2}+27 D_{1}^{2}-12 D_{2}+27 D_{2}^{2}-6 D_{1}(2+3\right.$ \\
& $\left.\left.D_{2}\right)-6 D_{0}\left(2+3 D_{1}+3 D_{2}\right)\right) k$ \\
\hline
\end{tabular}

\begin{tabular}{|c|c|}
\hline Mode & Current RMS \\
\hline Mode 1 & $1 / 6\left(-6 D_{1}^{3}-8 D_{1} D_{2} \mathrm{k}+D_{1}^{2}\left(4+9 D_{2} \mathrm{k}\right)-D_{2} \mathrm{k}\left(-9 D_{0}^{2}+D_{2}\left(-3 D_{2}-4 \mathrm{k}+6 D_{2} \mathrm{k}\right)\right)\right)$ \\
\hline Mode 2 & $\begin{array}{c}1 / 12\left(3 D_{1}^{3}(-4+\mathrm{k})+D_{1}\left(9 D_{0}^{2}+18 D_{0} D_{2}+D_{2}\left(-16+9 D_{2}\right)\right) \mathrm{k}+D_{1}^{2}\left(8-9 D_{0} \mathrm{k}+9\right.\right. \\
\left.\left.D_{2} \mathrm{k}\right)+\mathrm{k}\left(-3 D_{0}^{3}+9 D_{0}^{2} D_{2}-9 D_{0} D_{2}^{2}+D_{2}^{2}\left(3 D_{2}+8 \mathrm{k}-12 D_{2} \mathrm{k}\right)\right)\right) \\
\end{array}$ \\
\hline Mode 3 & $\begin{array}{c}1 / 216\left(27 D_{1}^{3}(-8+\mathrm{k})+9 D_{1}\left(-4+9 D_{0}^{2}-20 D_{2}+9 D_{2}^{2}+6 D_{0}\left(2+3 D_{2}\right)\right) \mathrm{k}-\right. \\
9 D_{1}^{2}\left(-16+3\left(-2+9 D_{0}-3 D_{2}\right) \mathrm{k}\right)+\mathrm{k}\left(8-81 D_{0}^{3}-36 D_{2}+27 D_{0}^{2}\left(2+3 D_{2}\right)-9 D_{0}\right. \\
\left.\left.\left(4-12 D_{2}+27 D_{2}^{2}\right)-27 D_{2}^{3}(-1+8 \mathrm{k})+18 D_{2}^{2}(3+8 \mathrm{k})\right)\right)\end{array}$ \\
\hline
\end{tabular}

Table 2. The current RMS expressions of the three modes.

\section{Optimal control method in light load conditions}

\subsection{Current stress optimal control}

The current stress expression is relatively simple and easy to optimize calculation. It affects the design of the transformer, and is also related to the cost of the switches. Besides, there is usually a switching action at the current peak time. The switches are turned off at the current peak value, and there will be a large turn-off loss. Therefore, the current stress is also related to the loss of the converter. This paper calculates the minimum current stress based on the Lagrange multiplier method. Also take Mode 2 as an example. The objective function and constraint conditions are as follows:

Objective function: $\quad I_{\max p u}=D_{0}+D_{2}(-1+k)$

Transmission power: $\quad P_{0}=-(1 / 4)\left(D_{0}^{2}+\left(D_{1}-D_{2}\right)^{2}-2 D_{0}\left(D_{1}+D_{2}\right)\right) k$

Boundary conditions: $\quad D_{1}-D_{2}<D_{0}<2 / 3-D_{1}-D_{2} \& D_{0}<D_{1}+D_{2} \& 0 \leq D_{2} \leq D_{1} \leq \frac{1}{3}$

\subsection{Current RMS optimal control}

The current RMS expression is more complicated, but it is directly related to the copper loss and the on-state loss of the switches. Therefore, the efficiency of the converter can be 
evaluated more comprehensively. At the same time, the RMS value of the inductor current can also reflect the power return of the converter.

The expression of the current RMS of the inductor current is more complicated than the expression of the current stress. Therefore, it is not easy to obtain the symbolic solution expression for it, and it is necessary to use a numerical optimization method to carry it out. In this paper, the Nelder-Mead numerical optimization algorithm is used to calculate the three variables of the phase shift duty cycle corresponding to the minimum current stress in different modes.
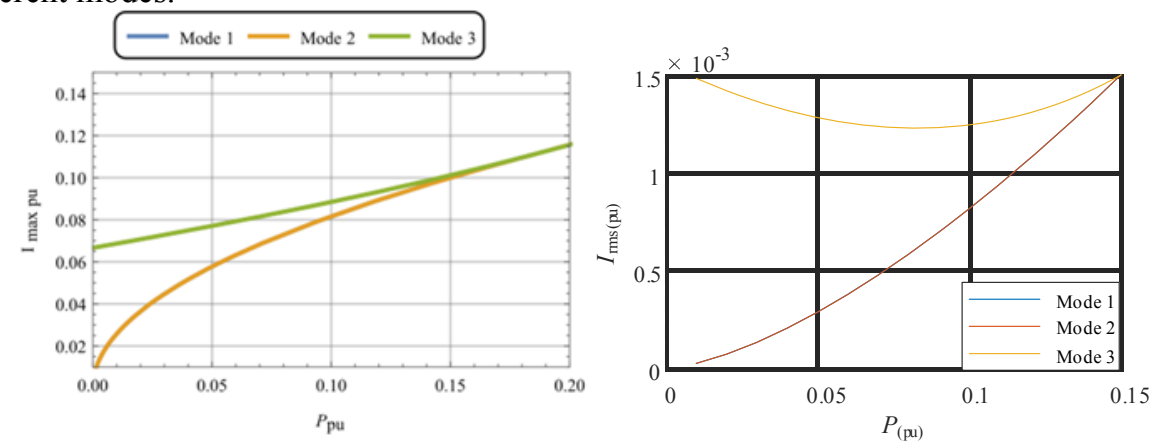

Fig. 4. Current stress and current RMS optimization results of different modes.

According to the results of current stress and current RMS, it can be seen that in these three modes the optimization results of Mode 1 and Mode 2 are the same. They have the minimum current stress and current RMS at this time. The three variables in Mode 1 and Mode 2 satisfy the following equations:

$$
\left\{\begin{array}{c}
\frac{D_{1}}{D_{2}}=k \\
D_{0}=D_{1}-D_{2}
\end{array}\right.
$$

\section{Experiment verification}

In order to verify the effectiveness, a prototype is built according to the parameters in Table. 3 for experimental verification.

Table 3. Experimental parameters.

\begin{tabular}{|c|c|}
\hline Parameter & Value \\
\hline Input voltage $U_{\mathrm{i}} / \mathrm{V}$ & 500 \\
\hline Output voltage $U_{\mathrm{o}} / \mathrm{V}$ & 750 \\
\hline Switching frequency $f / \mathrm{Hz}$ & $50 \mathrm{k}$ \\
\hline Transformer ratio $N$ & $0.8: 1$ \\
\hline leakage inductance value $L / \mu \mathrm{H}$ & 6.4 \\
\hline
\end{tabular}




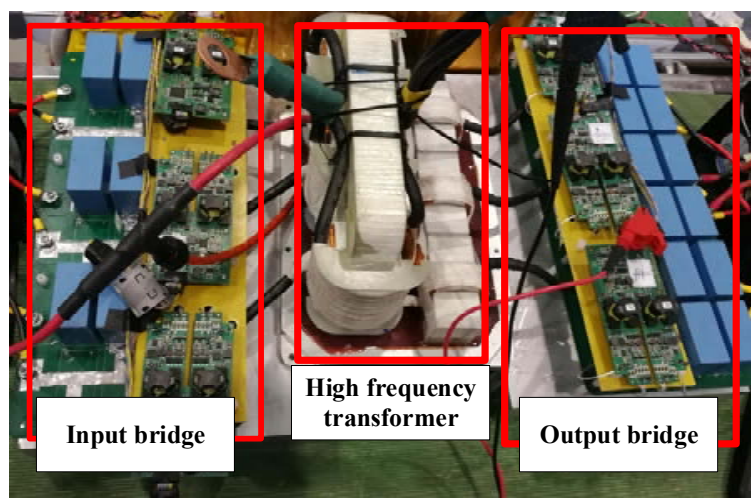

Fig. 5. Experimental prototype.

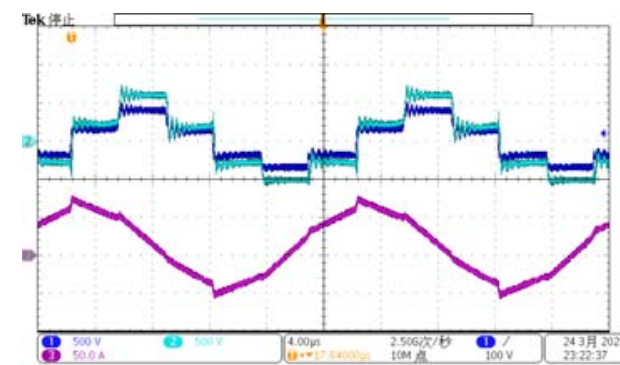

a) SPS control

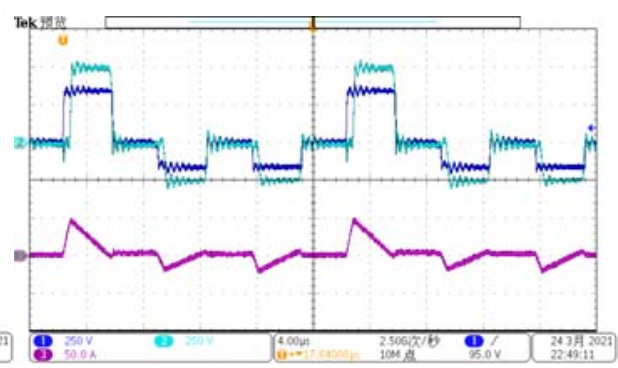

b) the control method proposed

Fig. 6. The experimental results of $4.2 \mathrm{~kW}$ SPS control and the control method proposed.

Fig. 6 is a comparison of the results of two control methods with input $500 \mathrm{~V}$, output $750 \mathrm{~V}$, and power of $4.2 \mathrm{~kW}$. The dark blue waveforms are the primary side phase voltage, the light blue waveforms are the secondary side phase voltage, and the purple waveforms are inductive current. It can be seen that the control method proposed in this paper has lower inductor current stress and current RMS than the traditional single-phase-shift control under light load conditions, which proves its effectiveness.

\section{Conclusion}

In order to solve the problems of the $3 \mathrm{p}-\mathrm{DAB}$ converter under light load conditions, a current optimal control method is proposed through the analysis and calculation of the current stress and RMS. It can realize both the optimal of the inductor current stress and RMS under the same transmission power, which effectively improves the overall performance of the converter under light load conditions, and is of great significance to the engineering application of the $3 \mathrm{p}-\mathrm{DAB}$ converter.

\section{Acknowledgments}

This work is partly supported by the Science and Technology Foundation of State Grid Corporation of China (no. 5206002000DB). 


\section{References}

1. Berg, M., Roinila, T. Dynamic Effect of Input-Voltage Feedforward in Three-Phase Grid-Forming Inverters. Energies 2020, 13, 2923.

2. Dogra R., Rajpurohit B., Tummuru N., Marinova I., Mateev V., Superimposed Component based Fault Detection Scheme for Multi-port DC Microgrid, IEEE International Conference on Power Electronics, Drives and Energy Systems (PEDES), 2020, pp. 1-6.

3. Hoek, H. V., et al. "Enhanced operating strategy for a three-phase dual-active-bridge converter including frequency variation." IEEE International Conference on Power Electronics \& Drive Systems IEEE, 2015.

4. Su, G. J., and L. Tang. "A Three-Phase Bidirectional DC-DC Converter for Automotive Applications." IEEE Industry Applications Society Meeting. IEEE, 2014.

5. Hu, J., et al. "A duty-cycle control method to ensure soft-switching operation of a high-power three-phase dual-active bridge converter." 2017 IEEE 3rd International Future Energy Electronics Conference and ECCE Asia (IFEEC 2017 - ECCE Asia) IEEE, 2017.

6. Huang, J., et al. "Simultaneous PWM control to operate the three-phase dual active bridge converter under soft switching in the whole load range." Conference Proceedings - IEEE Applied Power Electronics Conference and Exposition - APEC.

7. Huang, J., et al. "Optimized Modulation and Dynamic Control of Three-Phase Dual Active Bridge Converter with Variable Duty Cycles." IEEE Transactions on Power Electronics PP.3(2019):1-1.

8. Jiao H, Hao R, Lan Z, et al. Research on Three-degree-of-freedom Control of Threephase Dual Active Bridge to Minimize Current Stress[C]// 2021 IEEE 4th International Electrical and Energy Conference (CIEEC). IEEE, 2021. 